\title{
2DEG-HEATED AIGaN/GaN MICRO-HOTPLATES FOR HIGH-TEMPERATURE CHEMICAL SENSING MICROSYSTEMS
}

\author{
M. Hou ${ }^{l *}$, A.J. Suria ${ }^{2}$, A.S. Yalamarthy ${ }^{2}$, H. So ${ }^{3}$, and D. G. Senesky ${ }^{l, 3}$ \\ Departments of ${ }^{1}$ Electrical Engineering, ${ }^{2}$ Mechanical Engineering, and ${ }^{3}$ Aeronautics \& Astronautics \\ Stanford University, USA
}

\begin{abstract}
Fully-suspended AlGaN/GaN micro-hotplates that leverage self-heating of the two-dimensional electron gas (2DEG) have been modeled, micro-fabricated, and characterized at elevated ambient temperatures (from $25^{\circ} \mathrm{C}$ to $600^{\circ} \mathrm{C}$ in air). An input power of $\sim 75 \mathrm{~mW}$ heated the micro-hotplates to approximately $270^{\circ} \mathrm{C}$ from $25^{\circ} \mathrm{C}$ ambient conditions. In addition, finite element analysis (FEA) showed high-temperature uniformity across the micro-hotplate $(<1 \%$ variation) and fast transient response times ( $\sim 2 \mathrm{~ms}$ rise and fall times). These results support the use of the $\mathrm{AlGaN} / \mathrm{GaN}$-on-Si platform for high-temperature activation of chemical sensing catalysts and in-situ chemical sensing within high-temperature environments (e.g., combustion exhaust,
\end{abstract} industrial process, and downhole).

\section{INTRODUCTION}

The global market of chemical sensors is forecasted to reach about 31 billion US dollars by 2020 [1]. Data collected by chemical sensors can aid in emission control, energy savings, environmental monitoring, and catastrophe prevention [2-5]. For chemical sensing, a functional sensing layer (catalyst) transduces the chemical signals into electrical signals, which are then detected by the underlying sensor platform. To ensure reliable signals and reduced baseline drift, the sensing layer needs to be regenerated (burned off) periodically at elevated temperatures. In addition, many functional sensing materials exhibit increased sensitivity at elevated temperatures. For example, $\mathrm{ZnO}$ nanorods demonstrated enhanced sensitivity to hydrogen at approximately $250^{\circ} \mathrm{C}$ [6]. To sustain elevated temperatures during operation, a heating element is often integrated into the sensor system. Micro-hotplates, which are suspended and thermally isolated (reduced power consumption) structures with embedded heaters, are often utilized.

Commonly used micro-hotplates are composed of silicon oxide/nitride membranes and metallic heaters. Such systems suffer from reliability issues caused by electro-migration of metal atoms [7]. In addition, localized stress and voids in metal traces often lead to premature rupture of the membranes and drift of the heating characteristics [7]. In addition, micro-hotplates with metal heaters often employ complex heater geometries to achieve uniform temperature distribution [8]. Thus, micro-hotplates made from doped semiconductor materials (e.g., $\mathrm{Si}$ and $\mathrm{SiC}$ ) have been used to mitigate the reliability issues caused by metal electro-migration. Additionally, as the semiconductor plate itself serves as the heater, such micro-hotplates can produce uniform temperature distributions using simple layout geometries. For high-temperature chemical sensing $\left(>300^{\circ} \mathrm{C}\right)$, self-heated silicon carbide $(\mathrm{SiC})$ micro-hotplates have been developed, but custom substrates and advanced membrane release chemistry are required [9], which makes integration with electronics challenging.

In contrast, the self-heated $\mathrm{AlGaN} / \mathrm{GaN}$ micro-hotplates reported here utilize commercial $\mathrm{AlGaN} / \mathrm{GaN}$-on-Si wafers and a common $\mathrm{Si}$ release process $\left(\mathrm{XeF}_{2}\right)$, which supports monolithic integration with $\mathrm{GaN}$ electronics and high-temperature operation. Monolithic GaN-based microsystems are appealing for sensing applications in harsh environments, such as combustion exhaust

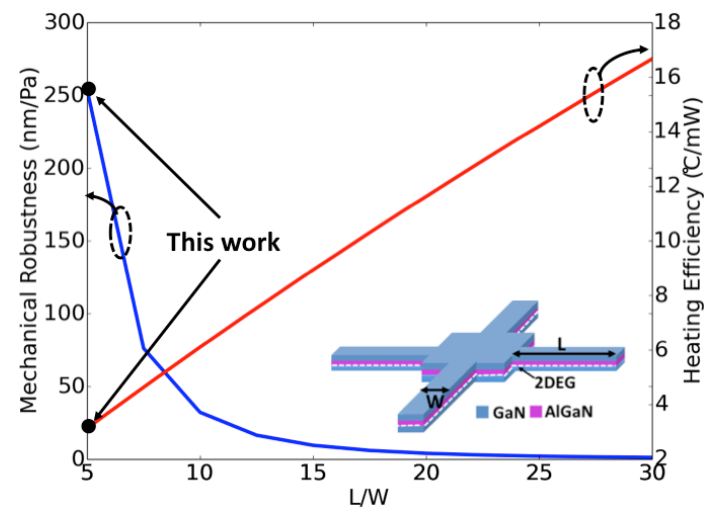

Figure 1: The influence of heater arm geometry on heating efficiency and mechanical robustness (out-of-plane displacement per unit perpendicularly applied pressure) of four-arm micro-hotplates studied by analytical modeling and FEA.

pipes, industrial manufacturing processes, and oil \& gas wellbores, due to the inherent temperature- and chemical-tolerance of GaN. $\mathrm{AlGaN} / \mathrm{GaN}$ heterostructures have been commercialized for high-frequency and high-power electronics thanks to the highly conductive two-dimensional electron gas (2DEG) at the $\mathrm{AlGaN} / \mathrm{GaN}$ interface [10]. In addition, the $2 \mathrm{DEG}$ is sensitive to surface charges and thus can be used for chemical sensing applications [11-12]. Moreover, due to the wide bandgap of GaN, $\mathrm{AlGaN} / \mathrm{GaN}$ devices have demonstrated successful operation up to $600^{\circ} \mathrm{C}$ [13]. Furthermore, GaN energy harvesters and resonators [14-15] leveraging the piezoelectric properties of $\mathrm{GaN}$ can also be integrated on a single chip to make self-powered wireless sensing nodes. This paper presents the modeling, micro-fabrication, and characterization (interpolation-based) of the first 2DEG-heated $\mathrm{AlGaN} / \mathrm{GaN}$ micro-hotplate architecture reported in the literature. In addition, uncertainty analysis of the characterization method and future work are discussed.

\section{DESIGN AND MODELING}

Analytical modeling and finite element analysis (FEA) were used to predict the effect of micro-hotplate geometry on heating efficiency (maximum temperature rise per unit input power) and mechanical robustness (maximum out-of-plane displacement per unit perpendicularly applied pressure) (Fig. 1). The results reveal that increasing the ratio of the heater arm length (L) to width (W) can enhance the heating efficiency but reduces the mechanical robustness of the micro-hotplate. It should be noted that the mechanical robustness falls at a much faster rate than the heating efficiency improves. To ensure that the micro-hotplate has sufficient mechanical robustness, $\mathrm{L} / \mathrm{W}=5$ was chosen for this work $(\mathrm{L}=100 \mu \mathrm{m}$ and $\mathrm{W}=20 \mu \mathrm{m})$. For this work, a spiral four-arm layout was chosen due to the fact that given the same $\mathrm{L} / \mathrm{W}$, a spiral four-arm micro-hotplate (Fig. 2a) spans a much smaller area than a conventional four-arm design (schematic shown in the inset of Fig. 1) while maintaining a similar heating efficiency and mechanical robustness. To ensure reliable operation, the thermal stress in the spiral four-arm micro-hotplate 

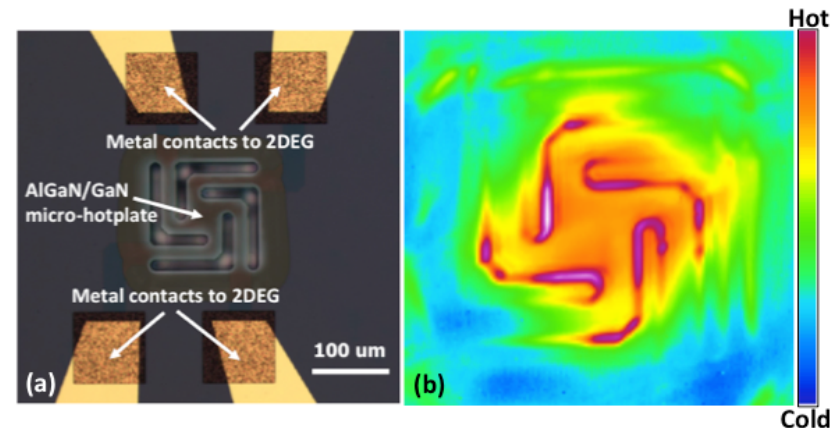

Figure 2: Optical image of a microfabricated AlGaN/GaN micro-hotplates (a), and infrared (IR) image of a micro-hotplate showing the temperature profile during operation (b).

Table 1. Material properties used in FEA.

\begin{tabular}{l|l}
\hline Thermal conductivity & $130 \mathrm{~W} /(\mathrm{m}-\mathrm{K})[16]$ \\
\hline Electrical conductivity & $\begin{array}{l}815 \mathrm{~S} / \mathrm{m} \text { for design phase; } \\
\text { Temperature dependent for } \\
\text { micro-hotplate characterization }\end{array}$ \\
\hline Young's modulus & $300 \mathrm{GPa}[17]$ \\
\hline Poisson's ratio & $0.23[18]$ \\
\hline $\begin{array}{l}\text { Coefficient of thermal } \\
\text { expansion (CTE) }\end{array}$ & Temperature dependent [19] \\
\hline Heat capacity & $491 \mathrm{~J} /(\mathrm{kg}-\mathrm{K})[16]$ \\
\hline Density & $6.15 \times 10^{3} \mathrm{~kg} / \mathrm{m}^{3}[20]$ \\
\hline
\end{tabular}

should be smaller than the yield stress of the GaN membrane. For the geometry of $\mathrm{L}=100 \mu \mathrm{m}$ and $\mathrm{W}=20 \mu \mathrm{m}$, the maximum von Mises computed by FEA was approximately $630 \mathrm{MPa}$ when the plate is heated to $330^{\circ} \mathrm{C}$ (ambient temperature at $25^{\circ} \mathrm{C}$ ). This is lower than the yield stress of $\mathrm{GaN}$ at that temperature $(>1000$ $\mathrm{MPa}$ [21]. The maximum stress occurs at the intersection of the plate and the heater arms.

Detailed FEA (COMSOL Multiphysics ${ }^{\circledR}$ ) of the spiral four-arm $\mathrm{AlGaN} / \mathrm{GaN}$ micro-hotplate was conducted taking into account the nominal microfabricated geometry ( $\mathrm{GaN}$ membrane thickness $=3 \mu \mathrm{m}$, heater arm length $=100 \mu \mathrm{m}$, heater arm width $=$ $20 \mu \mathrm{m}$, and central plate size $=50 \mu \mathrm{m}$ by $50 \mu \mathrm{m}$ ). In addition, the temperature-dependent properties (electrical conductivity of 2DEG and coefficient of thermal expansion) were utilized. The material properties of the micro-hotplates modeled in FEA are summarized in Table 1. Using these properties, the temperature profiles of the micro-hotplate (nominal geometry) were computed and the temperature profiles were visualized. The FEA results showed very high temperature uniformity across the main plate $(\sim 1 \%$ variation) in agreement with the infrared (IR) images taken during operation Fig. 2b. In addition, the FEA transient simulation results (Fig. 3) reveal that the micro-hotplate has fast heating (rise) and cooling (fall) transient response times $(\sim 2 \mathrm{~ms})$.

\section{MICROFABRICATION}

The micro-hotplates were fabricated on commercial GaN-capped AlGaN/GaN-on-Si wafers grown by metal-organic chemical vapor deposition (MOCVD). The wafer had a sheet resistance of $\sim 409 \Omega / \square$ at room temperature. The electron mobility was measured to be $\sim 1400 \mathrm{~cm}^{2} / \mathrm{V}$-s and the sheet electron density $\sim 0.9 \times 10^{13} \mathrm{~cm}^{-2}$. The fabrication process (Fig. 4) starts with a mesa etch using a chlorine/boron chloride $\left(\mathrm{Cl}_{2} / \mathrm{BCl}_{3}\right)$ plasma to define the $2 \mathrm{DEG}$ heater geometry. Then, $\mathrm{Ti} / \mathrm{Al} / \mathrm{Pt} / \mathrm{Au}$ metal contacts were e-beam evaporated and pattered with lift-off. A rapid thermal anneal at $850^{\circ} \mathrm{C}$ for 35 seconds in a $\mathrm{N}_{2}$ ambient was conducted to

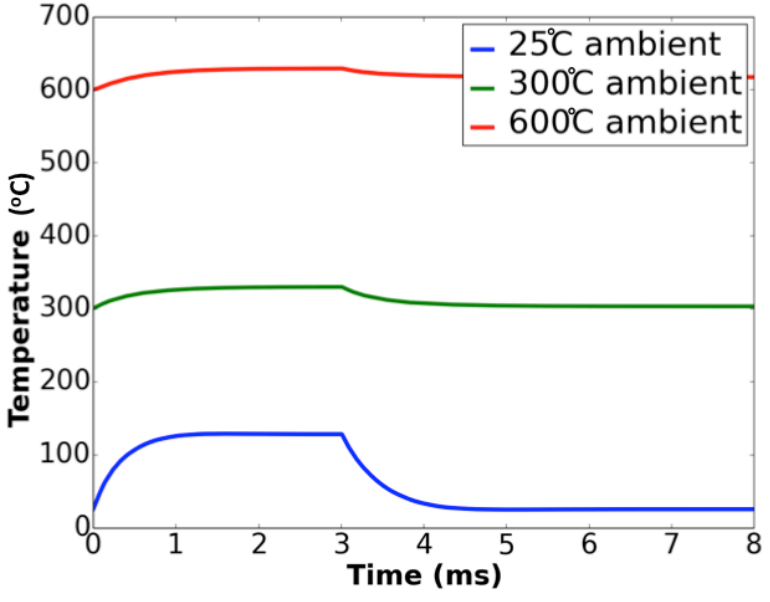

Figure 3: Simulated transient responses of spiral four-arm AlGaN/GaN micro-hotplate. In the simulation, a heating voltage $(15 \mathrm{~V})$ was applied at $t=0$, and removed at $t=3 \mathrm{~ms}$.

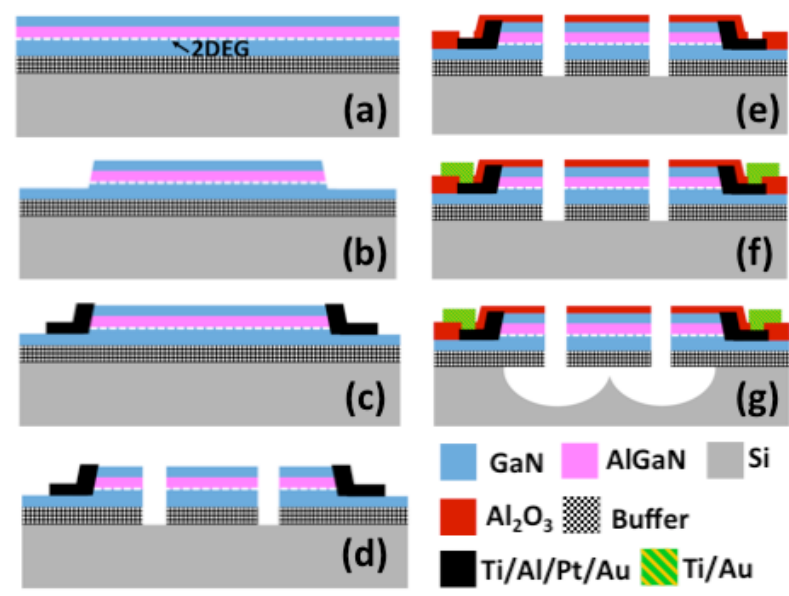

Figure 4: Process used to micro-fabricate the fully-suspended AlGaN/GaN micro-hotplate with 2DEG heater.

make the contacts Ohmic and improve reliability at high temperatures [22]. Silicon dioxide $\left(\mathrm{SiO}_{2}\right)$ was then deposited by plasma-enhanced chemical vapor deposition (PECVD). The GaN and buffer layers were patterned with $\mathrm{Cl}_{2} / \mathrm{BCl}_{3}$ plasma using the PECVD $\mathrm{SiO}_{2}$ hard mask to define the micro-hotplate membrane shapes. The $\mathrm{SiO}_{2}$ was stripped with buffered oxide etch (BOE) after the plasma etch. Then, alumina $\left(\mathrm{Al}_{2} \mathrm{O}_{3}\right)$ was deposited with plasma-enhanced atomic layer deposition (PE-ALD) for passivation of the micro-hotplate surface. $\mathrm{Al}_{2} \mathrm{O}_{3}$ was later patterned with $\mathrm{BOE}$ to expose metal contacts for interconnection, and to expose the gaps between the 2DEG heater arms and the central plate for later $\mathrm{XeF}_{2}$ release of the membrane. The micro-hotplate membrane was released from $\mathrm{Si}$ substrate with $\mathrm{XeF}_{2}$ vapor. The optical image of a fabricated $\mathrm{AlGaN} / \mathrm{GaN}$ micro-hotplate is shown in Fig. 2a with a surface temperature map during operation ( $\sim 90 \mathrm{~mW}$ power input) imaged by an infrared camera (Fig. 2b). 


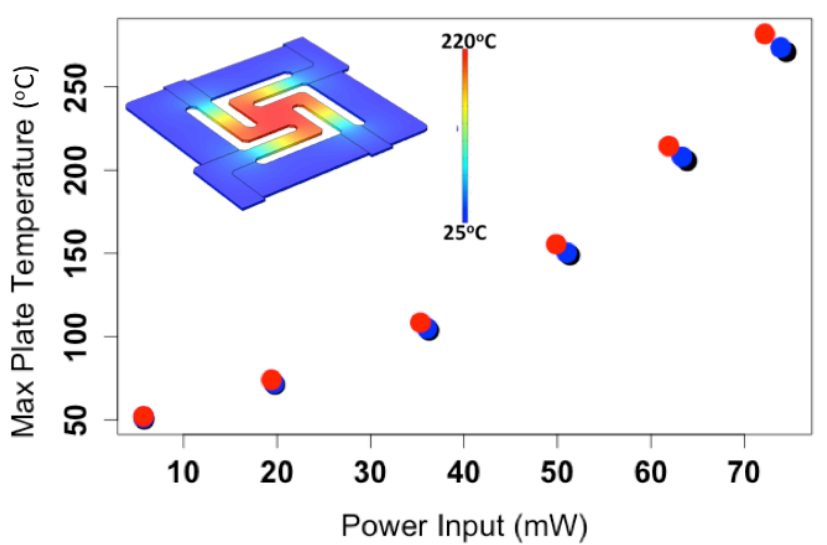

Figure 5: Interpolated heating characteristics of three microfabricated AlGaN/GaN micro-hotplates at ambient temperature of $25^{\circ} \mathrm{C}$. The inset shows the simulated temperature profile of the micro-hotplate.

\section{CHARACTERIZATION}

The AlGaN/GaN micro-hotplates were electrically characterized at various ambient temperatures (from $25^{\circ} \mathrm{C}$ to $600^{\circ} \mathrm{C}$ ) in air using a high temperature probe station (Signatone Inc.) and a semiconductor parameter analyzer (Agilent B1500A). Interpolation of electrical measurements and FEA simulation results were used to approximate the maximum plate temperatures. The characterization procedure is as follows:

- The electrical resistance values of several micro-hotplates were measured at various ambient temperatures up to $600^{\circ} \mathrm{C}$ in air.

- A numerical fit of the measured resistances versus ambient temperature was obtained using a least-squares quadratic model.

- The temperature-dependent electrical resistivity was calculated from the fitted quadratic model and fed into the FEA model (the model is shown in the inset of Fig. 5).

- The FEA model was used to compute the maximum plate temperatures $\left(\mathrm{T}_{\max }\right)$ achieved by applying various voltages at various ambient temperatures, as well as the total current flowing through the micro-hotplate. The resistance $(\mathrm{R})$ of the micro-hotplate was then calculated by dividing the applied voltages with the corresponding currents.

- The $\mathrm{R}$ versus $\mathrm{T}_{\max }\left(\mathrm{R}-\mathrm{T}_{\max }\right)$ curves at various ambient temperatures were obtained, and fitted with least-square linear regression models.

- The resistance values of the micro-hotplates under various applied voltages at various ambient temperatures were measured using the high-temperature probe station and SPA.

- The maximum plate temperatures of the micro-hotplates at different ambient temperatures were interpolated using the fitted $\mathrm{R}-\mathrm{T}_{\max }$ curves and the measured resistances.

The characterization results using the interpolation method are shown in Figs. 5 and 6. As shown in Fig. 5, an input power of $\sim 75 \mathrm{~mW}$ generates a maximum plate temperature of about $270^{\circ} \mathrm{C}$ in $25^{\circ} \mathrm{C}$ ambient temperatures. This corresponds to a heating efficiency of about $3^{\circ} \mathrm{C} / \mathrm{mW}$, which can be further increased by geometry optimization (Fig. 1). The fabricated micro-hotplates demonstrated successful heating operation at elevated ambient temperatures $\left(300^{\circ} \mathrm{C}\right.$ to $\left.600^{\circ} \mathrm{C}\right)$ in air using a high-temperature probe station (Fig. 6). As the ambient temperature is increased, the maximum temperature rise on the plate with respect to the ambient

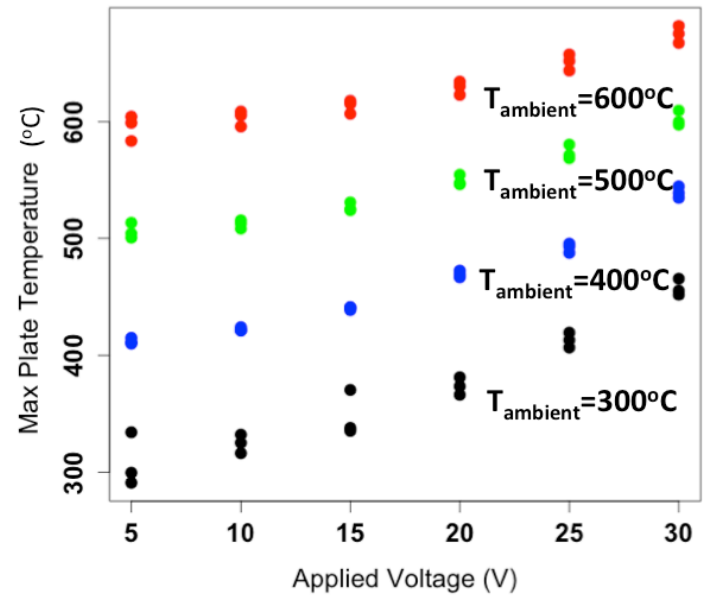

Figure 6: Operation of multiple AlGaN/GaN micro-hotplates at elevated ambient temperatures up to $600^{\circ} \mathrm{C}$ in air.

Table 2: Summary of uncertainty analysis of the maximum temperature values obtained from the characterization procedure.

\begin{tabular}{l|l}
\hline Error source & Estimated Error \\
\hline $\begin{array}{l}\text { The error induced by the } \\
\text { simplifying assumptions made in } \\
\text { FEM }\end{array}$ & $\begin{array}{l}\text { Average } \sim 3.4 \% \\
(\text { Max } \sim 9 \%)\end{array}$ \\
\hline FEM convergence & $<0.1 \%$ \\
\hline $\begin{array}{l}\text { Error in quadratic fit of measured } \\
\text { resistances }\end{array}$ & $\begin{array}{l}\text { Average } \sim 2.6 \% \\
\text { (Max } \sim 9 \%)\end{array}$ \\
\hline $\begin{array}{l}\text { Uncertainty induced by the } \\
\text { variation in released membrane } \\
\text { width }(10 \mu m \text { variation) }\end{array}$ & $\sim 0.13 \%$ \\
\hline $\begin{array}{l}\text { Error induced by the uncertainty } \\
\text { in thermal conductivity and } \\
\text { geometric parameters }\end{array}$ & $\begin{array}{l}\text { Approx. zero } \\
\text { (Fig. 9) }\end{array}$ \\
\hline Neglecting contact resistance & $<0.25 \%$ \\
\hline SPA measurement error & Approx. zero \\
\hline Chuck temperature reading error & $\begin{array}{l}<4 \%\left(1{ }^{\circ} \mathrm{C} \text { error at }\right. \\
\left.25^{\circ} \mathrm{C}\right)\end{array}$ \\
\hline $\begin{array}{l}\text { Error in linear fit of R- } \mathrm{T}_{\max } \\
\text { calibration curves }\end{array}$ & $\begin{array}{l}\text { Average } \sim 0.15 \% \\
(\text { Max } \sim 0.2 \%)\end{array}$ \\
\hline Total & $\begin{array}{l}\text { Average } \sim 11 \% \\
(\text { Max } \sim 22 \%)\end{array}$ \\
\hline
\end{tabular}

temperature is decreased because the mobility of electrons in 2DEG is decreased due to increased phonon scattering [23]. Thus, the electrical conductivity of $2 \mathrm{DEG}$ is decreased and less current can be pumped through into the micro-hotplates for self-heating at higher temperatures. Nevertheless, $\mathrm{T}_{\max }$ of $\sim 680^{\circ} \mathrm{C}$ was achieved in $600^{\circ} \mathrm{C}$ ambient with an applied voltage of $30 \mathrm{~V}$ (Fig. 6).

\section{UNCERTAINTY ANALYSIS}

The uncertainty sources for the maximum plate temperatures obtained from the characterization procedure are summarized in Table 2. The total average uncertainty was estimated to be approximately $11 \%$. The three most significant sources of uncertainty are 1) neglecting heat loss to air and radiation in FEA, 2) least-square quadratic fitting of measured resistance values with respect to ambient temperatures, and 3) the error in chuck temperature readings. It should be noted that the uncertainties in the thermal conductivity, thickness and 2D layout geometry of the micro-hotplate do not induce errors in the FEA-computed $\mathrm{R}-\mathrm{T}_{\max }$ curves. This is validated by the FEA: the $\left(R, T_{\max }\right)$ pairs resulting 
from different thermal conductivities, thicknesses, and L/W values all fall on one single curve, which is the one generated by varying the voltages applied to a nominal device geometries with material properties summarized in Table 2.

\section{DISCUSSION AND CONCLUSION}

2DEG-heated AlGaN/GaN micro-hotplates have been modeled, microfabricated, and characterized in this work. A heating efficiency of approximately $3^{\circ} \mathrm{C} / \mathrm{mW}$ has been achieved by the device prototypes, which is a suitable activation power for many sensing applications. To further improve the heating efficiency, longer and thinner heater arms can be utilized. In addition, to preserve mechanical robustness while enhancing heating efficiency, spring-shapes (or "zigzag" shapes) heater arm layout can be employed. A reduction in heating voltage for a certain maximum plate temperature can be achieved by reducing the sheet resistance of the $\mathrm{AlGaN} / \mathrm{GaN}$ heterostructure through material optimization. Sheet resistances values of near $300 \Omega$ / and lower have been reported in literature [24]. In conclusion, 2DEG-heated micro-hotplates have been successfully fabricated and operated in air and demonstrated heating temperatures as high as $680^{\circ} \mathrm{C}$ (from $600^{\circ} \mathrm{C}$ ambient temperature), supporting the development of monolithic AlGaN/GaN microsystems for in-situ chemical sensing in high-temperature environments.

\section{ACKNOWLEDGEMENTS}

The authors would like to acknowledge the support of Dr. Philippe Jansen and Texas Instruments Inc. (TI).

\section{REFERENCES}

[1] The Global Chemical Sensors Market: Trends, Drivers and Projections 2015. [Online]. Available: http://www.strategyr.com/MarketResearch/Chemical_Sen sors_Market_Trends.asp. [Accessed: 30-Mar-2016].

[2] S. A Akbar, P. Dutta, and C. Lee, "High-Temperature Ceramic Gas Sensors: A Review," Appl. Ceram. Technol., vol. 3, no. 4, pp. 302-311, 2006.

[3] H. So, M. Hou, S. R. Jain, J. Lim, and D. G. Senesky, "Interdigitated Pt-GaN Schottky interfaces for high-temperature soot-particulate sensing," Appl. Surf. Sci., vol. 368, pp. 104-109, 2016.

[4] G. W. Hunter, P. G. Neudeck, C. C. Liu, et al., "Development of Chemical Sensor Arrays for Harsh Environments and Aerospace Applications," in Proceedings of IEEE Sensors, 2002, vol. 2, pp. 11261133.

[5] M. T. Soo, K. Y. Cheong, and A. F. M. Noor, "Advances of SiC-based MOS capacitor hydrogen sensors for harsh environment applications," Sensors Actuators B. Chem., vol. 151, no. 1, pp. 39-55, 2010.

[6] J. X. Wang, X. W. Sun, Y. Yang, et al., "Hydrothermally grown oriented $\mathrm{ZnO}$ nanorod arrays for gas sensing applications," Nanotechnology, vol. 17, pp. 4995-4998, 2006.

[7] J. Courbat, D. Briand, and N. F. de Rooij, "Reliability improvement of suspended platinum-based micro-heating elements," Sensors Actuators, A Phys., vol. 142, pp. 284291, 2008.

[8] P. Bhattacharyya, "Technological Journey Towards Reliable Microheater Development for MEMS Gas Sensors: A Review," IEEE Trans. Device Mater. Reliab., vol. 14, no. 2, pp. 589-599, Jun. 2014.

[9] G. Benn, "Design of a silicon carbide micro-hotplate geometry for high temperature chemical sensing," MIT, 2001.

[10] U. K. Mishra and P. Parikh, "AlGaN/GaN HEMTs-an overview of device operation and applications," Proc. IEEE, vol. 90, no. 6, pp. 1022-1031, Jun. 2002.

[11] S. J. Pearson, B. S. Kang, S. Kim, et al, "GaN-based diodes and transistors for chemical, gas, biological and pressure sensing," J. Phys. Condens. Matter, vol. 16, pp. R961-R994, 2004.

[12] P. Offermans and R. Vitushinsky, " $\mathrm{NO}_{2}$ Detection with AlGaN/GaN 2DEG Channels for Air Quality Monitoring," IEEE Sens. J., vol. 13, no. 8, pp. 2823 2827, 2013.

[13] I. Daumiller, C. Kirchner, M. Kamp, K. J. Ebeling, and E. Kohn, "Evaluation of the Temperature Stability of AlGaN/GaN Heterostructure FET's," vol. 20, no. 9, pp. 448-450, 1999.

[14] K. Brueckner, F. Niebelschuetz, K. Tonisch, et al., "Two-dimensional electron gas based actuation of piezoelectric $\mathrm{AlGaN} / \mathrm{GaN}$ microelectromechanical resonators," Appl. Phys. Lett., vol. 93, p. 173504, 2008.

[15] A. Ansari, V. J. Gokhale, J. Roberts, and M. Rais-Zadeh, "Monolithic integration of GaN-based micromechanical resonators and HEMTs for timing applications," in 2012 International Electron Devices Meeting, 2012.

[16] R. Quay, "III-N Materials, and the State-of-the-Art of Devices and Circuits," in Gallium Nitride Electronics, Springer, 2008, p. 22.

[17] C. Nam, P. Jaroenapibal, D. Tham, et al., "Diameter-Dependent Electromechanical Properties of GaN Nanowires," Nano Lett., vol. 6, no. 2, pp. 153-158, 2006.

[18] C. Kisielowski, J. Krüger, S. Ruvimov, et al., "Strain-related phenomena in GaN thin films.," Phys. Rev. B. Condens. Matter, vol. 54, no. 24, pp. 17745-17753, Dec. 1996.

[19] M. Leszczynski, T. Suski, H. Teisseyre, et al., "Thermal expansion of gallium nitride," J. Appl. Phys., vol. 76, no. 8, pp. 4909-4911, 1994.

[20] V. Cimalla, J. Pezoldt, and O. Ambacher, "Group III nitride and $\mathrm{SiC}$ based MEMS and NEMS: materials properties ," J. Phys. D Appl. Phys., vol. 40, pp. 63866434, 2007.

[21] I. Yonenaga and K. Motoki, "Yield strength and dislocation mobility in plastically deformed bulk single-crystal GaN Yield strength," J. Appl. Phys., vol. 90, no. 12 , pp. 6539-6541, 2001.

[22] M. Hou and D. G. Senesky, "Operation of ohmic $\mathrm{Ti} / \mathrm{Al} / \mathrm{Pt} / \mathrm{Au}$ multilayer contacts to $\mathrm{GaN}$ at $600{ }^{\circ} \mathrm{C}$ in air," Appl. Phys. Lett., vol. 105, no. 8, 081905, 2014.

[23] L. Hsu and W. Walukiewicz, "Electron mobility in AlxGa1-xN/GaN heterostructures," Phys. Rev. B, vol. 56, no. 3, pp. 1520-1528, 1997.

[24] J. W. Johnson, E. L. Piner, A. Vescan, et al., "12 W/mm AlGaN-GaN HFETs on Silicon Substrates," IEEE Electron Device Lett., vol. 25, no. 7, pp. 459-461, 2004.

\section{CONTACT}

*M. Hou, tel: +1-650-796-9522; mmhou@stanford.edu 